\title{
A structured understanding of cellobiohydrolase I binding to poplar lignin fractions after dilute acid pretreatment
}

Lan Yao ${ }^{1,2,4}$, Chang Geun Yoo ${ }^{3}$, Xianzhi Meng ${ }^{4}$, Mi Li $^{3}$, Yunqiao Pư ${ }^{3}$, Arthur J. Ragauskas ${ }^{3,4,5^{*}}$ (1) and Haitao Yang ${ }^{1,2^{*}}$

\begin{abstract}
Background: Cellulase adsorption to lignin is considered a cost barrier for bioethanol production; however, its detailed association mechanism is still not fully understood. In this study, two natural poplar variants with high and low sugar release performance were selected as the low and high recalcitrant raw materials (named $L$ and $H$, respectively). Three different lignin fractions were extracted using ethanol, followed by $p$-dioxane and then cellulase treatment from the dilute acid pretreated poplar solids (fraction 1, 2, and 3, respectively).

Results: Each lignin fraction had different physicochemical properties. Ethanol-extracted lignin had the lowest weight average molecular weight, while the molecular weights for the other two lignin fractions were similar. ${ }^{31} \mathrm{P}$ NMR analysis revealed that lignin fraction with higher molecular weight contained more aliphatic hydroxyl groups and less phenolic hydroxyl groups. Semi-quantitative analysis by 2D HSQC NMR indicated that the lignin fractions isolated from the natural variants had different contents of syringyl (S), guaiacyl $(G)$ and interunit linkages. Lignin extracted by ethanol contained the largest amount of $S$ units, the smallest amounts of $G$ and $p$-hydroxybenzoate (PB) subunits, while the contents of these lignin subunits in the other two lignin fractions were similar. The lignin fraction obtained after cellulase treatment was primarily comprised of $\beta-0-4$ linkages with small amounts of $\beta-5$ and $\beta-\beta$ linkages. The binding strength of these three lignin fractions obtained by Langmuir equations were in the order of $L_{1}>L_{3}>L_{2}$ for the low recalcitrance poplar and $H_{1}>H_{2}>H_{3}$ for the high recalcitrance poplar.
\end{abstract}

Conclusions: Overall, adsorption ability of lignin was correlated with the sugar release of poplar. Structural features of lignin were associated with its binding to CBH. For natural poplar variants, lignin fractions with lower molecular weight and polydispersity index (PDI) exhibited more CBH adsorption ability. Lignins with more phenolic hydroxyl groups had higher CBH binding strength. It was also found that lignin fractions with more condensed aromatics adsorbed more CBH likely attributed to stronger hydrophobic interactions.

Keywords: Cellobiohydrolase I, Enzyme binding, Lignin, Dilute acid pretreatment, Poplar

\footnotetext{
*Correspondence: aragausk@utk.edu; pphtyang1979@aliyun.com

${ }^{1}$ School of Pulp \& Paper Engineering, Hubei University of Technology, Wuhan 430068, China

${ }^{3}$ Joint Institute for Biological Sciences, Biosciences Division, Oak Ridge

National Laboratory, Oak Ridge, TN 37831, USA

Full list of author information is available at the end of the article
} 


\section{Background}

Lignin is a major component in the cell wall of terrestrial plants and usually constitutes about $15-30 \%$ of its total dry weight. It plays an important role in the structural integrity and protection from microorganism attack [1]. Unlike plant polysaccharides (i.e., cellulose and hemicellulose), lignin is a three-dimensional cross-linked macromolecular polymer composed of phenylpropanoid units, typically derived from guaiacyl, syringyl and/or $p$-hydroxyphenyl, connected by $\mathrm{C}-\mathrm{C}$ and $\mathrm{C}-\mathrm{O}$ interunit linkages [2]. The contents of guaiacyl (G), syringyl (S) and $p$-hydroxyphenyl $(\mathrm{H})$ units in lignin varies from species to species, which are commonly used to categorize the three major types of biomass, softwood lignin mainly contains $\mathrm{G}$ unit, hardwood lignin is composed of both $\mathrm{G}$ and $\mathrm{S}$ units, and the lignin from herbaceous origins is composed of $\mathrm{G}$ and $\mathrm{S}$ units as well as lesser amounts of $\mathrm{H}$ units [3].

Lignin is considered as a major barrier that hinders the commercialization process of biomass to biofuel production, as it is chemically and physically associated with cellulose and hemicellulose [4]. The negative effects of lignin on cellulase performance were first identified in 1980s [5, 6]. Recently, increased research efforts have been conducted in this field to make biomass utilization economically and technically feasible [7]. These studies have reported several important findings including the fact that a higher phenolic hydroxyl content can result in an increased lignin cellulase adsorption capacity [8-10], and a higher carboxylic acid group content of the associated lignin can enhance the enzymatic hydrolysis of lignocellulosic biomass $[11,12]$. Overall, it has been proposed that cellulase binds to lignin through three major interactions: hydrophobicity $[11,13]$, hydrogen bonding [14] and electrostatic interactions [12]. Furthermore, it was reported that lignin composition could also influence the enzymatic hydrolysis process [3]. However, inconsistent results were reported about the effect of S/G ratio on cellulase adsorption. Some researchers found that a high $\mathrm{S} / \mathrm{G}$ ratio is favorable for the hydrolysis yield, because of the higher binding capability of $\mathrm{G}$ over $\mathrm{S}$ to cellulase [15, 16], while others indicated that lignin with higher S/G ratio had higher cellulase binding ability [17]. As a result, further studies are needed to clarify the mechanisms leading to the inconsistent results.

The aerobic fungus Trichoderma is a common source of enzymes used in cellulase production. The research on cellulase from Trichoderma reesei and its binding to lignin have been studied in recent years. Nonaka found that lignin from steam-exploded pretreated eucalyptus adsorbed more $T$. reesei cellulase than lignin from native eucalyptus [18]. Adsorption of T. reesei cellulase on softwood lignin-based lignophenol indicated that cellulase adsorption on lignin is single-layered and phenolic hydroxyl could enhance cellulase binding [19]. Binding of CBH I and EG II purified from $T$. reesei to steam pretreated softwood (SPS) were compared. The results showed that more of CBH I was absorbed by SPS [20]. However, reports on cellulase from Trichoderma longibrachiatum are limited.

In this study, two 4-year-old natural poplar variants harvested under uniform conditions from Clatskanie, Oregon were selected as the raw materials. The two native poplar variants showed different glucose release performance upon treatment with cellulase. During enzymatic hydrolysis, the low recalcitrance poplar $(L)$ released twice the amount of glucose than the high recalcitrance poplar $(H)$ did [21]. Up till now, detailed mechanism about cellulase binding to lignin still has not been fully elucidated, which is largely attributable to the structural complexity and heterogeneity of lignin. Hence, a simple fractionation approach of lignin is needed. Here, solvents were chosen based on their chemical nature, polarity and ability to form hydrogen bonds with lignin. To investigate the effects of lignin characteristics on cellulase-lignin interactions, the acid pretreated poplar was sequentially extracted to generate lignin fraction samples with different reactivity or structural properties. Pretreated poplar samples were extracted with ethanol to obtain the first lignin fraction. Then, the solid residue was further extracted with $96 \%$ dioxane to acquire the second lignin fraction and the third fraction of lignin was collected by treating the remaining solid residue with cellulase followed by extraction with dioxane. Fourier transform infrared (FT-IR), gel permeation chromatographic (GPC) and nuclear magnetic resonance (NMR) were employed to study the structural characteristics of different lignin samples. Cellobiohydrolase I (CBH), which was the protein in the filtrates of cultured fungi responsible most for cellulose hydrolysis [22], was then used to investigate the binding properties of the three different lignin fractions. Finally, the relationship between lignin structural features and $\mathrm{CBH}$ binding properties was analyzed accordingly.

\section{Results and discussion \\ FT-IR analysis}

The FT-IR spectra of six lignin fractions are shown in Fig. 1. The assignments of major signals were based on published literatures $[15,23,24]$. The strong signal at $3410 \mathrm{~cm}^{-1}$ was ascribed to hydroxyl bond $(\mathrm{O}-\mathrm{H})$ stretching and the absorption at $2938 \mathrm{~cm}^{-1}$ was from $\mathrm{C}-\mathrm{H}$ stretching vibrations. Signals centered at about 1596, 1513 and $1424 \mathrm{~cm}^{-1}$ corresponding to aromatic rings were clearly observed in all lignin samples. 


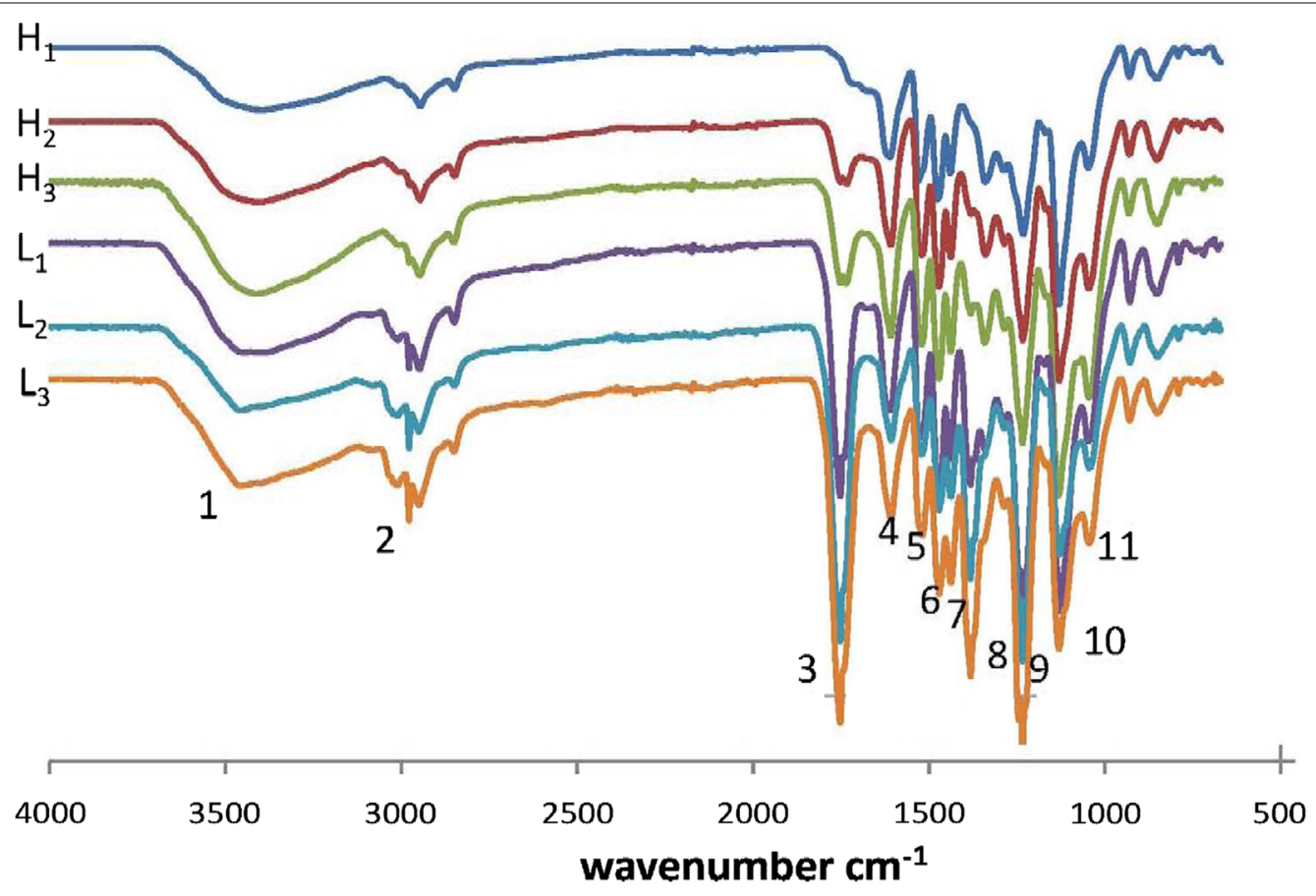

Fig. 1 FT-IR spectra of lignin fractions from natural poplar variants

The absorption at $1459 \mathrm{~cm}^{-1}$ was attributed to the $\mathrm{C}-\mathrm{H}$ asymmetric deformations. The signals at 1324 and $1112 \mathrm{~cm}^{-1}$ were corresponded to syringyl/condensed guaiacyl and aromatic $\mathrm{C}-\mathrm{H}$ deformation of syringyl unit, respectively. The absorption bands at around $1215 \mathrm{~cm}^{-1}$ belonged to $\mathrm{C}-\mathrm{O}$ stretching of guaiacyl unit. It indicated that the lignin samples from natural poplar variants were G-S type. The band at $1030 \mathrm{~cm}^{-1}$ was attributed to aromatic $\mathrm{C}-\mathrm{H}$ in-plane deformation vibrations.
The relative signal intensities of various functional groups were calculated as ratios referenced to the intensity of band at $1513 \mathrm{~cm}^{-1}$ (Table 1). It was found that the most obvious difference was the signal at around $1738 \mathrm{~cm}^{-1}$, which was ascribe to $\mathrm{C}=\mathrm{O}$ in unconjugated ketones. This substructure was the least in the ethanolextractable lignin fraction and the most in the lignin fraction recovered after cellulase treatment in both poplars. Previous studies on fractionation of degraded lignins from the black liquor of Eucalyptus pellita also revealed

Table 1 Signal assignment and relative intensities of lignin fractions from natural poplar variants in FT-IR spectra

\begin{tabular}{|c|c|c|c|c|c|c|c|c|}
\hline No. & Assignment & $\begin{array}{l}\text { Wavenumber } \\
\left(\mathrm{cm}^{-1}\right)\end{array}$ & $H_{1}$ & $H_{2}$ & $H_{3}$ & $L_{1}$ & $L_{2}$ & $L_{3}$ \\
\hline 1 & Hydroxyl group & 3410 & 0.49 & 0.68 & 0.75 & 0.57 & 0.73 & 0.73 \\
\hline 2 & $\mathrm{C}-\mathrm{H}$ stretching & 2938 & 0.47 & 0.67 & 0.64 & 0.65 & 0.89 & 0.85 \\
\hline 3 & $\mathrm{C}=\mathrm{O}$ in unconjugated ketone & 1738 & 0.13 & 0.54 & 0.69 & 1.29 & 2.36 & 2.25 \\
\hline 4 & Aromatic ring & 1596 & 0.83 & 0.98 & 1.00 & 0.86 & 0.93 & 0.95 \\
\hline 5 & Aromatic ring & 1513 & 1.00 & 1.00 & 1.00 & 1.00 & 1.00 & 1.00 \\
\hline 6 & $\mathrm{C}-\mathrm{H}$ deformation & 1459 & 1.14 & 1.27 & 1.27 & 1.24 & 1.37 & 1.36 \\
\hline 7 & Aromatic ring & 1424 & 0.95 & 1.06 & 1.10 & 1.10 & 1.34 & 1.35 \\
\hline 8 & Syringyl and condensed guaiacyl & 1324 & 1.01 & 1.06 & 1.06 & 1.05 & 1.06 & 1.08 \\
\hline 9 & C-O stretching & 1215 & 1.39 & 1.66 & 1.66 & 1.85 & 2.41 & 2.37 \\
\hline 10 & Aromatic $\mathrm{C}-\mathrm{H}$ deformation in syringyl & 1112 & 1.89 & 1.96 & 2.00 & 1.85 & 1.76 & 1.78 \\
\hline 11 & $\mathrm{C}-\mathrm{O}-\mathrm{C}$ stretching & 1030 & 0.91 & 1.29 & 1.39 & 1.01 & 1.14 & 1.10 \\
\hline
\end{tabular}

The relative intensity was calculated as the ratio of the intensity of the band to the intensity of band at $1513 \mathrm{~cm}^{-1}$ 
that lignin fraction extracted by $n$-propanol showed stronger absorption at $1711 \mathrm{~cm}^{-1}$ [25]. In addition, the singal intensity of $\mathrm{C}-\mathrm{O}$ was the least in the ethanolextractable lignin fraction, while those of the other two lignin fractions were similar.

\section{Molecular weight analysis}

Prior to GPC analysis, the lignin fractions were acetylated to facilitate their dissolution in THF [26]. The weight average molecular weights $\left(M_{w}\right)$, number average molecular weights $\left(M_{n}\right)$, and polydispersity index (PDI) $\left(M_{w} / M_{n}\right)$ of the lignins are presented in Table 2. It was found that the ethanol-extractable lignin fractions from the dilute acid pretreated poplar had the lowest molecular weights. The $M_{w}$ for $L_{1}$ and $H_{1}$ lignin fractions were 1649 and $1570 \mathrm{~g} / \mathrm{mol}$, respectively. The $M_{w}$ of the other two lignin fractions were higher $(4437,3354,4196$ and 3975 for $L_{2}, L_{3}$ and $H_{2}, H_{3}$ lignin fractions, respectively) than the ethanol-extractable lignin fractions. These results indicated that the ethanol-extracted lignin fractions could represent the low molecular weight lignin, while the other two fractions were representative of the bulk and residual lignin. The PDI of all lignin samples was narrow (less than 2) and significant difference between the variants was not observed. The results were consistent with previous studies on lignin from poplar [27], which indicated that after dilute acid pretreatment, the weight average molecular weight was around 7500 , while number average molecular weight was about 3000 . Due to the fractionation of lignin from poplar, lignin fractions in the present study showed narrower PDI and lower molecular weight. The lower molecular weight in the present study was also caused by the lower solid/liquid ratio and more acid used in the pretreatment process.

\section{${ }^{31} \mathrm{P}$ NMR analysis}

In this study, to investigate the major hydroxyl group contents in each lignin fraction, the lignin samples were derivatized with 2-chloro-4,4,5,5-tetramethyl-1,3,2dioxaphospholane (TMDP) [25]. The phosphitylated

Table 2 Molecular weights and PDI of lignin fractions from dilute acid pretreated natural poplar variant

\begin{tabular}{llll}
\hline Sample & $\boldsymbol{M}_{\boldsymbol{n}}$ & $\boldsymbol{M}_{\boldsymbol{w}}$ & PDI $\left(\boldsymbol{M}_{\boldsymbol{w}} / \boldsymbol{M}_{\boldsymbol{n}}\right)$ \\
\hline$L_{1}$ & $1007 \pm 35$ & $1649 \pm 113$ & $1.64 \pm 0.06$ \\
$L_{2}$ & $2310 \pm 3$ & $4437 \pm 1$ & $1.92 \pm 0.00$ \\
$L_{3}$ & $1828 \pm 97$ & $3354 \pm 248$ & $1.83 \pm 0.04$ \\
$H_{1}$ & $886 \pm 2$ & $1570 \pm 12$ & $1.77 \pm 0.00$ \\
$H_{2}$ & $2263 \pm 8$ & $4196 \pm 37$ & $1.86 \pm 0.01$ \\
$H_{3}$ & $2336 \pm 131$ & $3975 \pm 277$ & $1.78 \pm 0.02$ \\
\hline
\end{tabular}

hydroxyl groups were measured by integrating the area of individual peaks compared to the known concentration of the internal standard $\mathrm{N}$-hydroxy-5-norbornene2,3-dicarboximide [28]. Figure 2 presents the contents of aliphatic hydroxyl groups, $\mathrm{C}_{5}$ substituted guaiacyl/syringyl phenolics and guaiacyl phenolic groups, $p$-hydroxyphenyl groups and carboxylic acids hydroxyl groups.

The results indicated that the aliphatic and $\mathrm{C}_{5}$ substituted phenolic (mainly from syringyl aromatics) hydroxyls were the major hydroxyls of all the lignin fractions. The amount of aliphatic hydroxyls increased in the order of $L_{1}<L_{2}<L_{3}, H_{1}<H_{2}<H_{3}$. On the other hand, the content of $\mathrm{C}_{5}$ substituted phenolics and syringyl hydroxyls increased in the opposite manner: $L_{3}<L_{2}<L_{1}$, $H_{3}<H_{2}<H_{1}$. Lignin fractions from acid pretreated poplar with higher molecular weights contained more aliphatic $\mathrm{OH}$ and less $\mathrm{C} 5$ substituted phenolics as previously reported [29]. It has been reported that the formation of lignin with relatively small molecular weight involves the formation of new phenolic hydroxyl groups and the elimination of aliphatic hydroxyl groups [30]. The ethanol-extracted lignin fractions had more $\mathrm{C}_{5}$ substituted phenolic groups (mainly from syringyl aromatics) than aliphatic hydroxyl groups. The dioxane-extracted lignin fractions exhibited comparable phenolic/hydroxyl characteristics, while the amount of aliphatic hydroxyl groups was higher than that of $C_{5}$ substituted phenolic groups (mainly from syringyl aromatics) in the third lignin fractions. The hydroxyl group contents in the same lignin fractions from different natural poplar variants did not show significant difference, except the content of carboxylic acid hydroxyls in $L_{3}$.

\section{HSQC NMR analysis}

To explore the structural characteristic of lignin fractions from natural poplar variants, 2D HSQC NMR analysis was conducted (Additional file 1: Figure S1). The cross peaks were assigned according to literatures [23, 27, 31, 32].

The signals from the aromatic region $\left(\delta_{\mathrm{C}} / \delta_{\mathrm{H}} 160-\right.$ 90/8.0-5.5 ppm) were assigned mainly to the unsubstituted carbons in aromatic rings of lignin units. The syringyl unit showed correlations for $\mathrm{C}_{2,6} / \mathrm{H}_{2,6}$ centered at around $\delta_{\mathrm{C}} / \delta_{\mathrm{H}} 103.1 / 6.60 \mathrm{ppm}$. The $\mathrm{C}_{2,6} / \mathrm{H}_{2,6}$ correlation of the $\alpha$-oxidized syringyl unit was shifted to $\delta_{\mathrm{C}} / \delta_{\mathrm{H}} 106.0 / 7.23 \mathrm{ppm}$. Cross peaks of condensed syringyl unit were found at around $\delta_{\mathrm{C}} / \delta_{\mathrm{H}} 105.4 / 6.42 \mathrm{ppm}$ [8]. The guaiacyl unit was evidenced by cross peaks for $\mathrm{C}_{2} / \mathrm{H}_{2}, \mathrm{C}_{5} / \mathrm{H}_{5}$ and $\mathrm{C}_{6} / \mathrm{H}_{6}$ centered at $\delta_{\mathrm{C}} / \delta_{\mathrm{H}} 110.2 / 6.91$, $114.7 / 6.69$, and $118.4 / 6.75 \mathrm{ppm}$, respectively. Cross peaks of condensed guaiacyl unit were found at around $\delta_{\mathrm{C}} / \delta_{\mathrm{H}}$ $112.0 / 6.65 \mathrm{ppm}$ [8]. Signal for $p$-hydroxyphenyl benzoate unit was observed by $\mathrm{C}_{2,6} / \mathrm{H}_{2,6}$ correlation at $\delta_{\mathrm{C}} / \delta_{\mathrm{H}}$ 


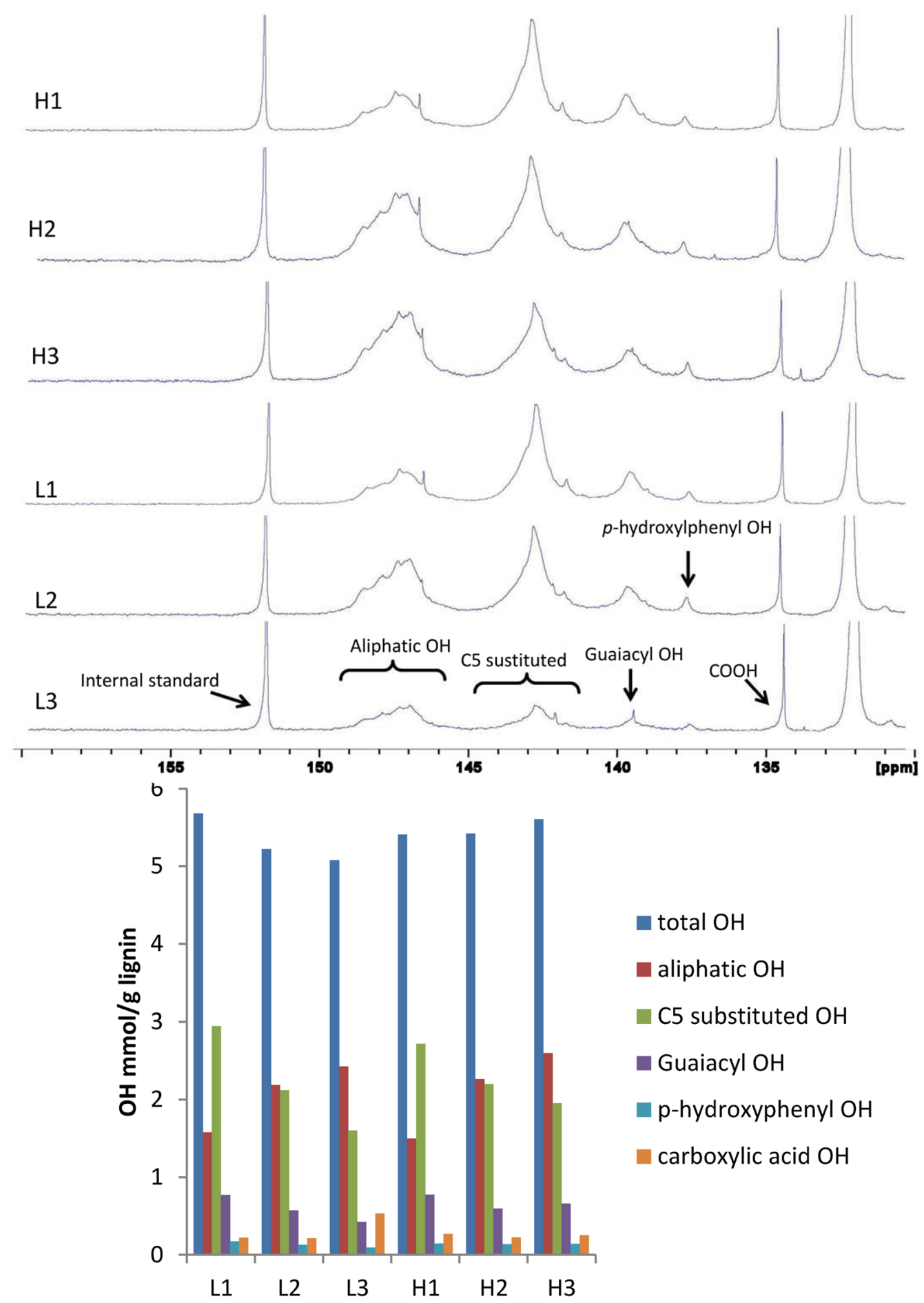

Fig. $2{ }^{31}$ P NMR spectra and analysis results of lignin fractions from natural poplar variants 
Table 3 Semi-quantitative information of lignin samples

\begin{tabular}{|c|c|c|c|c|c|c|c|}
\hline Lignin substructure & $\delta_{\mathrm{C}} / \delta_{\mathrm{H}}(\mathrm{ppm})$ & $\begin{array}{l}L_{1} \\
\%^{\mathrm{a}}\end{array}$ & $\begin{array}{l}L_{2} \\
\%^{\mathrm{a}}\end{array}$ & $\begin{array}{l}L_{3} \\
\%^{\mathrm{a}}\end{array}$ & $\begin{array}{l}H_{1} \\
\%^{\mathrm{a}}\end{array}$ & $\begin{array}{l}\mathrm{H}_{2} \\
\%^{\mathrm{a}}\end{array}$ & $\begin{array}{l}H_{3} \\
\%^{a}\end{array}$ \\
\hline S & $103.1 / 6.60$ & $32.4 \pm 1.8$ & $49.1 \pm 0.3$ & $48.2 \pm 0.8$ & $41.1 \pm 0.7$ & $38.5 \pm 0.2$ & $34.8 \pm 0.3$ \\
\hline$S^{\prime}$ & $106.0 / 7.23$ & $7.1 \pm 0.1$ & $7.7 \pm 0.0$ & $7.1 \pm 0.6$ & $8.5 \pm 0.2$ & $5.7 \pm 0.4$ & $5.5 \pm 0.0$ \\
\hline S condensed & $105.4 / 6.42$ & $45.3 \pm 1.2$ & $26.8 \pm 0.0$ & $29.0 \pm 0.0$ & $38.5 \pm 0.5$ & $39.8 \pm 0.1$ & $40.7 \pm 0.1$ \\
\hline Total S & - & $84.6 \pm 0.3$ & $83.6 \pm 0.3$ & $84.3 \pm 0.2$ & $88.1 \pm 0.0$ & $83.9 \pm 0.4$ & $81.0 \pm 0.1$ \\
\hline G & $110.2 / 6.91$ & $8.1 \pm 0.1$ & $14.5 \pm 0.0$ & $13.5 \pm 0.4$ & $9.5 \pm 0.0$ & $14.5 \pm 0.3$ & $16.6 \pm 0.0$ \\
\hline G condensed & $112.0 / 6.65$ & $7.3 \pm 0.6$ & $2.5 \pm 0.4$ & $2.1 \pm 0.2$ & $2.4 \pm 0.0$ & $1.6 \pm 0.0$ & $2.4 \pm 0.0$ \\
\hline Total G & - & $15.4 \pm 0.4$ & $17.0 \pm 0.4$ & $15.7 \pm 0.2$ & $11.2 \pm 0.0$ & $16.1 \pm 0.4$ & $19.0 \pm 0.1$ \\
\hline PB & $130.9 / 7.63$ & $7.5 \pm 0.0$ & $7.9 \pm 0.2$ & $9.5 \pm 0.3$ & $4.2 \pm 0.2$ & $6.0 \pm 0.7$ & $6.1 \pm 0.4$ \\
\hline$S / G$ & - & $5.5 \pm 0.1$ & $4.9 \pm 0.1$ & $5.4 \pm 0.1$ & $7.4 \pm 0.0$ & $5.2 \pm 0.1$ & $4.3 \pm 0.0$ \\
\hline$\beta-O-4$ & $71.6 / 4.85$ & $66.5 \pm 0.0$ & $71.2 \pm 0.7$ & $76.2 \pm 2.7$ & $59.5 \pm 1.0$ & $70.8 \pm 2.0$ & $74.9 \pm 1.0$ \\
\hline$\beta-5$ & $87.0 / 5.43$ & $11.7 \pm 0.0$ & $10.7 \pm 0.6$ & $6.7 \pm 0.8$ & $17.1 \pm 1.5$ & $9.5 \pm 0.7$ & $7.8 \pm 0.8$ \\
\hline$\beta-\beta$ & $85.0 / 4.63$ & $21.8 \pm 0.0$ & $18.1 \pm 1.3$ & $17.2 \pm 1.8$ & $23.4 \pm 0.4$ & $19.8 \pm 0.3$ & $17.3 \pm 0.2$ \\
\hline
\end{tabular}

a Amount of specific functional group was expressed as percentage of $S+G$ for $S, G$ and $P B$; of total side chain for $\beta-O-4, \beta-5$ and $\beta-\beta$

130.9/7.63 ppm. The quantitative information of various substructures in lignin fractions from natural poplar variants are presented in Table 3 . The content of total syringyl unit was the most in the ethanol-extracted lignin fractions, and the contents in the other two lignin fractions decreased slightly. On the contrary, the contents of $\mathrm{G}$ unit were higher in NO.2 and NO.3 lignin fractions $(16-19 \%)$ than that of NO.1 lignin (11-15\%). As a result, the $\mathrm{S} / \mathrm{G}$ ratios of ethanol-extracted lignin fractions were higher than that of the other two lignin fractions. The $p$-hydroxybenzoate, which may take part in lignification of cell wall [33], was also observed in all lignin samples with its contents higher in dioxane-extracted and cellulase-treated lignin fractions.

In the aliphatic region $\left(\delta_{\mathrm{C}} / \delta_{\mathrm{H}} 90-45 / 6.0-2.0 \mathrm{ppm}\right)$ of NMR spectra, the cross peaks of methoxyl and major interunit linkages such as $\beta$-aryl-ether $(\beta-O-4)$, phenylcoumaran $(\beta-5)$ and resinol $(\beta-\beta)$ were the most prominent ones. The $\mathrm{C}-\mathrm{H}$ correlations in $\beta-O-4$ substructure were confirmed by $\mathrm{C}_{\alpha} / \mathrm{H}_{\alpha}$ at $\delta_{\mathrm{C}} / \delta_{\mathrm{H}} 71.6 / 4.85 \mathrm{ppm}(\beta-O-4$ linked to a $\mathrm{S}$ unit) and 71.1/4.74 ppm ( $\beta-O-4$ linked to a $\mathrm{G}$ unit), $\mathrm{C}_{\beta} / \mathrm{H}_{\beta}$ at $\delta_{\mathrm{C}} / \delta_{\mathrm{H}} 85.9 / 4.11 \mathrm{ppm}(\beta-O-4$ linked to a $\mathrm{S}$ unit) and $83.4 / 4.28 \mathrm{ppm}(\beta-O-4$ linked to a $\mathrm{G}$ unit), $\mathrm{C}_{\gamma} / \mathrm{H}_{\gamma}$ at $\delta_{\mathrm{C}} / \delta_{\mathrm{H}} 59.7 / 3.67 \mathrm{ppm}$. The presence of phenylcoumaran was well-resolved for $\mathrm{C}_{\alpha} / \mathrm{H}_{\alpha}$ correlations at around $\delta_{\mathrm{C}} / \delta_{\mathrm{H}} 87.0 / 5.43 \mathrm{ppm}$. Lignin resinol was also observed by its $\mathrm{C}-\mathrm{H}$ correlations at $\delta_{\mathrm{C}} / \delta_{\mathrm{H}} 85.0 / 4.63 \mathrm{ppm}$ $\left(\mathrm{C}_{\alpha} / \mathrm{H}_{\alpha}\right), 53.6 / 3.06 \mathrm{ppm}\left(\mathrm{C}_{\beta} / \mathrm{H}_{\beta}\right)$, and $70.9 / 4.18 \mathrm{ppm}\left(\mathrm{C}_{\gamma} /\right.$ $\mathrm{H}_{\gamma}$ ). Apparently, signals associated with $\beta-O-4$ interunit linkages prominently appeared in all these lignin fractions, and the relative content was increased from $L_{1} / H_{1}$ lignin to $L_{3} / H_{3}$ lignin, while the relative contents of phenylcoumaran and resinol linkages were decreased.

\section{CBH adsorption to lignins by Langmuir equation}

To assess the binding ability between $\mathrm{CBH}$ and isolated lignin fractions, Langmuir adsorption isotherms of $\mathrm{CBH}$ with the different lignins were determined and are presented in Table 4. Binding strength is a parameter to estimate the enzymes onto lignins by incorporating both maximum adsorption capacity and equilibrium constant. The results showed that the binding strength of lignin fractions were 670,176, and $417 \mathrm{ml} / \mathrm{g}$ lignin for $L_{1}, L_{2}$ and $L_{3}$, and 556, 378 and $370 \mathrm{ml} / \mathrm{g}$ lignin for $H_{1}$, $\mathrm{H}_{2}$ and $\mathrm{H}_{3}$, respectively. The highest binding strength was observed for $L_{1}(670 \mathrm{ml} / \mathrm{g})$ and $H_{1}(556 \mathrm{ml} / \mathrm{g})$. The mass yields of each lignin fraction were 46.7, 50.0 and $3.3 \%$ for low recalcitrance poplar, while those from high recalcitrance poplar were 50.4, 46.8 and 2.8\%, respectively. Combining the results of lignin fraction yield and binding strength, it was found that the total binding ability of lignin from the two poplars were $414 \mathrm{ml} / \mathrm{g}$ (low recalcitrance poplar) and $467 \mathrm{ml} / \mathrm{g}$ (high recalcitrance poplar). The variations in the adsorption

Table 4 Langmuir adsorption isotherm parameters from $\mathrm{CBH}$ adsorption to lignins

\begin{tabular}{lcclc}
\hline & $\begin{array}{l}E_{\max } \\
(\mathbf{m g} / \mathbf{g})\end{array}$ & $\begin{array}{l}\boldsymbol{K}_{\text {ads }} \\
(\mathbf{m l} / \mathbf{m g})\end{array}$ & $\begin{array}{l}\text { Binding } \\
\text { strength } \\
\text { (ml/g lignin) }\end{array}$ & $\boldsymbol{R}^{\mathbf{2}}$ \\
\hline$L_{1}$ & 89.29 & 7.47 & 670 & 0.85 \\
$L_{2}$ & 33.44 & 5.25 & 176 & 0.99 \\
$L_{3}$ & 49.75 & 8.38 & 417 & 0.99 \\
$H_{1}$ & 52.91 & 10.5 & 556 & 0.99 \\
$H_{2}$ & 497.51 & 0.76 & 378 & 0.86 \\
$H_{3}$ & 188.68 & 1.96 & 370 & 0.99 \\
\hline
\end{tabular}


parameters for the lignin samples might be due to the different structure characteristic.

\section{The correlations between lignin structural characteristic and non-productive $\mathrm{CBH}$ adsorption factors}

The correlations of molecular weight and PDI of lignin on cellulase have been stated in previous studies [15,
21, 34]; however, the conclusions were not consistent. In the present study, lignin fraction from natural variant poplar with lower molecular weight and PDI showed more $\mathrm{CBH}$ binding ability, suggesting that lignin fraction with smaller molecular weight and lower PDI favoring $\mathrm{CBH}$ adsorption. As shown in Fig. $3 \mathrm{a}$ and $\mathrm{b}, M_{w}$ and PDI of lignin fractions were negatively correlated with
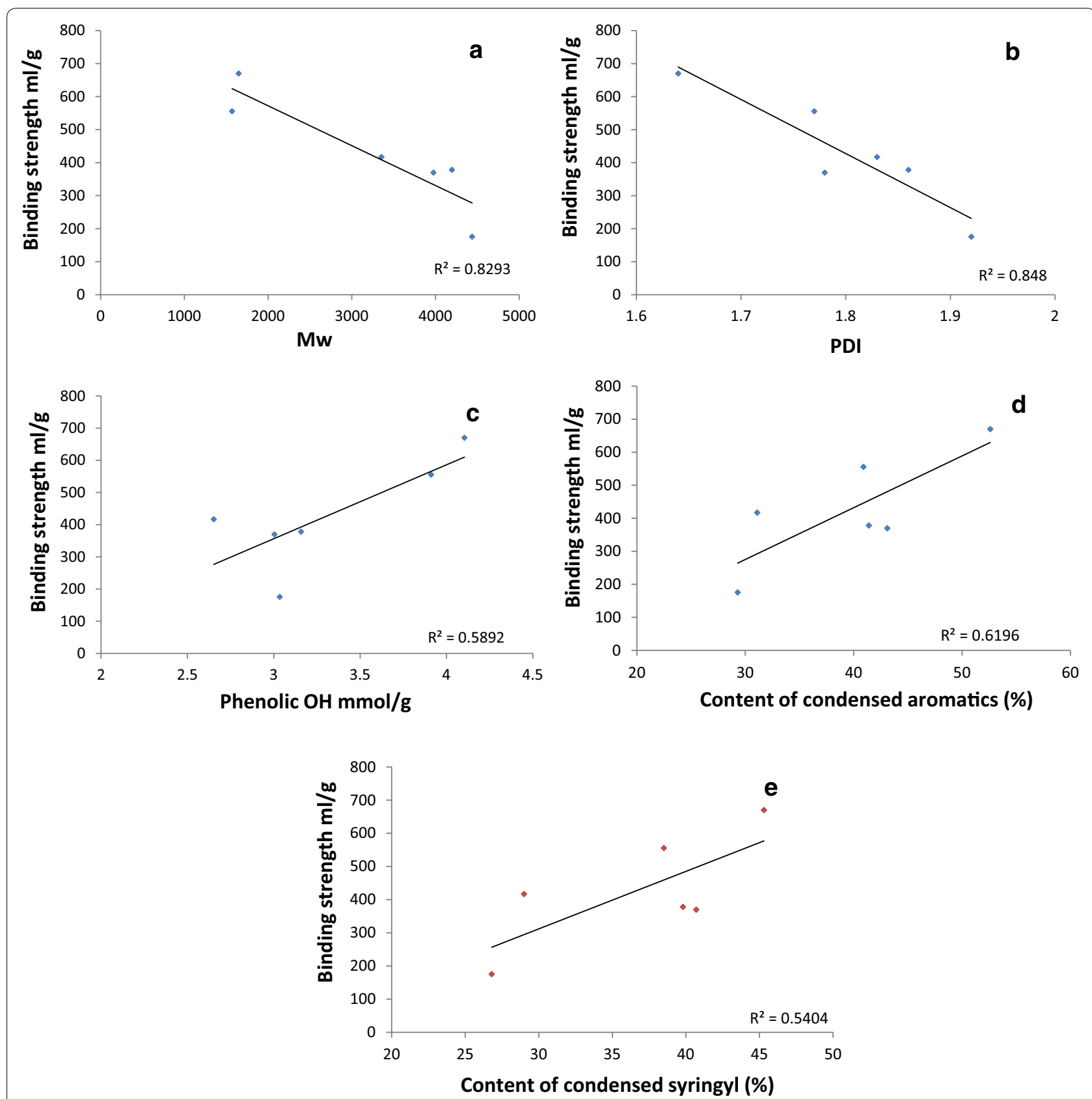

Fig. 3 Relationship between lignin physicochemical properties and binding strength between lignin and CBH (a relationship between lignin Mw and binding strength of lignin with $\mathrm{CBH}$; $\mathbf{b}$ relationship between lignin PDI and binding strength of lignin with $\mathrm{CBH}$; $\mathbf{c}$ relationship between the phenolic hydroxyl group contents and binding strength of lignin with $\mathrm{CBH} ; \mathbf{d}$ relationship between contents of condensed aromatics and binding strength of lignin with $\mathrm{CBH}$; e relationship between contents of condensed syringyl unit and binding strength of lignin with $\mathrm{CBH}$ ) 
binding strength between lignin and $\mathrm{CBH}$ (Pearson coefficient $=-0.911, R^{2}=0.83, p$ value $=0.012$ for $M_{w}$; Pearson coefficient $=-0.922, R^{2}=0.85, p$ value $=0.009$ for PDI). Previous studies also pointed out that more uniform fragment size is favorable for the interaction of lignin with proteins [15]. Earlier studies on natural poplar variant showed that there was relationship between lignin $M_{w}$ and glucose release [21], which was consistent with the present study.

It has been reported that hydroxyl groups, in particular phenolic hydroxyl groups, played an important role in cellulase binding to lignin [9]. Negative correlations of aliphatic hydroxyl group with cellulase adsorption [15] and hydrophobicity of lignin [12] were investigated in the previous studies. However, association between aliphatic hydroxyl group and $\mathrm{CBH}$ binding was not observed in this study. Instead, phenolic hydroxyl group in the lignin fractions showed a positive correlation with $\mathrm{CBH}$ adsorption ability. As shown in Fig. 3c, correlation between phenolic hydroxyl groups and binding strength was positive $\left(R^{2}=0.59\right.$, Pearson coefficient $=0.768, p$ value $\left.=0.075\right)$, suggesting that content of phenolic hydroxyl group affected the binding strength between lignin from poplar and $\mathrm{CBH}$. The results were consistent with previous studies $[9,10,15]$. It was reported that hydroxypropylation of phenolic $\mathrm{OH}$ can reduce the negative inhibitory effect of lignin on glucose release [9, 35]. Pretreated biomass with decreased phenolic $\mathrm{OH}$ was a contribution to an increased glucose yield [36]. Binding strength was negatively associated with enzymatic hydrolysis yield, indicating that greater binding strength between lignin and cellulase would result in less glucose yield [35]. It could be predicted that lignin fraction from natural poplar variant with more phenolic hydroxyl group would result in less glucose when cellulase hydrolysis was conducted. Li's research with vanillin, which was from degradation of lignin, and three other compounds with similar structure showed that inhibitory effect on cellulase was from phenolic hydroxyl groups of vanillin [37]. Phenolic hydroxyl group could interact with cellulase by forming hydrogen bonding with amino acid residue and interfering cellulase hydrolysis to cellulose.

The influence of condensed aromatics on CBH adsorption was also observed in this study (Fig. 3d). A positive association between condensed aromatics and binding strength of lignin fractions to $\mathrm{CBH}\left(R^{2}=0.62\right.$, Pearson coefficient $=0.787, p$ value $=0.063$ ) indicated that lignin fractions with more condensed aromatics could bind stronger with $\mathrm{CBH}$. Similarly, increase of cellulase adsorption with the degree of lignin condensation in the pretreated wood and bleached pulps was reported in the previous study [10]. In addition, Ko and coworkers reported that more condensed lignin coincided with increasing affinity of enzyme adsorption [16]. It is hypothesized that the increased degree of condensation would result in more cellulase adsorbed via hydrophobic interaction [38]. Furthermore, it was concluded that phenolic $\mathrm{OH}$ group in condensed syringyl and guaiacyl subunits have strong association with inhibitory effects on enzymatic hydrolysis [8]. However, only contents of condensed syringyl subunit showed a positive correlation between binding strength of lignin fractions and $\mathrm{CBH}$ $\left(R^{2}=0.54\right.$, Pearson coefficient $=0.735, p$ value $\left.=0.096\right)$ in this study (Fig. 3e).

\section{Conclusions}

The $\mathrm{CBH}$ adsorptions onto different lignin fractions from two Populus trichocarpa natural variants were investigated with the physicochemical properties of each lignin fractions. It was found that structural features of lignin have great effect on $\mathrm{CBH}$ binding. Also, molecular weight and PDI of lignin fractions were negatively correlated with $\mathrm{CBH}$ binding. The phenolic hydroxyl group content in the lignin fractions showed a positive correlation with $\mathrm{CBH}$ binding ability. In particular, the contents of total condensed aromatics and condensed syringyl of lignin fractions involved in the association of lignin with $\mathrm{CBH}$ likely do so by hydrogen bonding and hydrophobic interaction. The observation of correlations between lignin physicochemical properties and $\mathrm{CBH}$ adsorption in this study can be also used as a preliminary result for explaining the recalcitrance of $P$. trichocarpa natural variants.

\section{Methods \\ Materials}

Four-year-old $P$. trichocarpa natural variants were collected from a field site in Clatskanie, Oregon. The chemicals were purchased from Fisher (USA). Pronase was obtained from Sigma Chemical Company (USA). CBH was purchased by Megazyme (USA).

\section{Dilute acid pretreatment}

Populus trichocarpa natural variants were debarked, Wiley-milled (screen size $<2 \mathrm{~mm}$ was used), and extracted by toluene/ethanol $(2: 1, \mathrm{v} / \mathrm{v})$ for $8 \mathrm{~h}$. The extractives-free material was then pretreated by a 11 Parr pressure reactor (model 4560, Parr Instrument Company) with $0.5 \%$ sulfuric acid $(\mathrm{v} / \mathrm{v})$. The ratio of liquid to solid was 10:1. The pretreatment was kept at $160 \pm 2{ }^{\circ} \mathrm{C}$ for $10 \mathrm{~min}( \pm 0.5 \mathrm{~min})$. The stirring speed was set to $2.5 \mathrm{~Hz}$. The heating rate was about $3{ }^{\circ} \mathrm{C} / \mathrm{min}$. The reactor was quenched in an ice water bath for $10 \mathrm{~min}$ to stop the pretreatment process. The pretreated solid residue was acquired by filtration and washed with an excess of deionized water until pH was neutral. The pretreated poplars were then air-dried overnight at room temperature. 


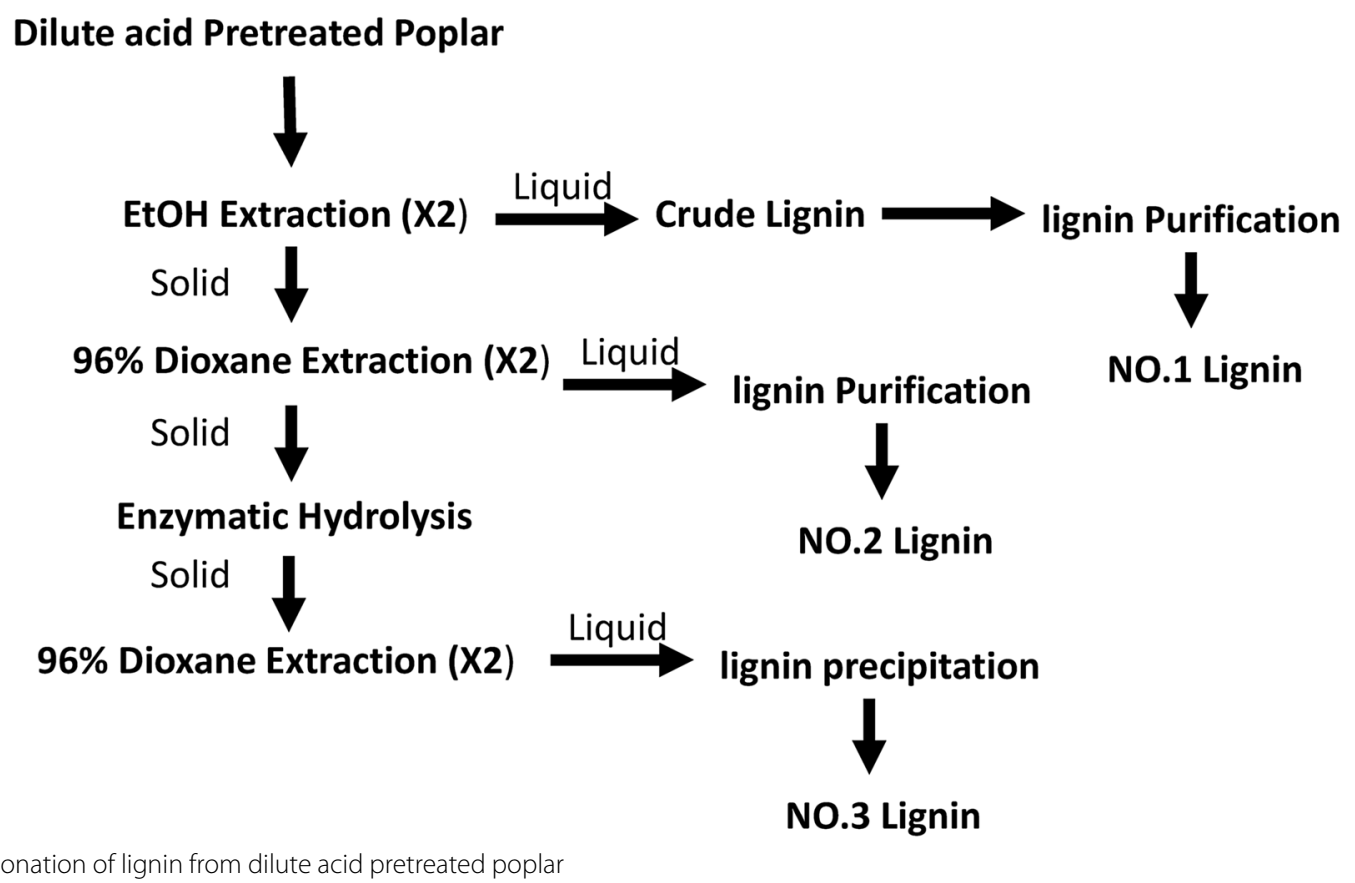

Fractionation of lignin from pretreated poplar natural variants

Three different lignin fractions were separated from the dilute acid pretreated $P$. trichocarpa natural variants as presented in Fig. 4, following the method described before [39]. Pretreated $P$. trichocarpa natural variants were first extracted twice with ethanol for $24 \mathrm{~h}$. The extract was rotary-evaporated and freeze-dried to obtain the crude NO.1 lignin $\left(L_{1}\right.$ and $\left.H_{1}\right)$.

The solid residue after the ethanol extraction was airdried and then extracted twice with $96 \%$ dioxane to provide crude NO.2 lignin $\left(H_{2}\right.$ and $\left.L_{2}\right)$.

The air-dried residue after two-step extraction was hydrolyzed by overloading cellulase to remove carbohydrates. After protease treatment to remove any remaining protein, it was extracted by dioxane-water mixture (96:4, $\mathrm{v} / \mathrm{v} ; 10 \mathrm{ml} / \mathrm{g}$ biomass) to get the crude lignin $L_{3}$ and $H_{3}$. The crude lignin was purified according to the method of milled wood lignin (MWL) [40].

\section{Fourier transform infrared (FT-IR) analysis}

FT-IR spectroscopy (Spectrum One FT-IR system, Perkin Elmer, Wellesley, MA) was employed to get the FT-IR spectra from 4000 to $650 \mathrm{~cm}^{-1} .64$ scans with $2 \mathrm{~cm}^{-1}$ resolution were signal averaged and stored.

\section{Gel permeation chromatographic (GPC) analysis}

Gel permeation chromatographic (GPC) analysis was conducted to determine the molecular weights of each lignin fraction. Lignin samples were acetylated prior to analysis according to method by Kumar [41]. Gel permeation chromatography was performed on an Agilent 1200 HPLC system (Agilent Technologies, Inc, Santa Clara, $\mathrm{CA}$ ) with tetrahydrofuran (THF) as described in the previous study [42].

\section{Nuclear magnetic resonance (NMR) analysis}

Around $50 \mathrm{mg}$ lignin samples fraction were dissolved in $0.4 \mathrm{ml} \mathrm{DMSO}-d_{6}$. Bruker Avance III $400-\mathrm{MHz}$ spectroscopy equipped with a 5-mm Broadband Observe probe (5-mm BBO $400 \mathrm{MHz}$ W1 with Z-gradient probe, Bruker) was employed to conduct two-dimensional (2D) ${ }^{1} \mathrm{H}-{ }^{13} \mathrm{C}$ heteronuclear single quantum coherence (HSQC) NMR experiment at $298 \mathrm{~K}$. A Bruker standard pulse sequence ('hsqcetgpsi2') was used with the following parameters: spectral width of $11 \mathrm{ppm}$ in F2 $\left({ }^{1} \mathrm{H}\right)$ with 2048 data points and $190 \mathrm{ppm}$ in $\mathrm{F} 1\left({ }^{13} \mathrm{C}\right)$ with 256 data points; 96 scans and 1-s delay.

${ }^{31} \mathrm{P}$ NMR spectra were obtained after derivatization of the lignin fractions with 2-chloro-4,4,5,5-tetramethyl-1,3,2-dioxaphospholane [28]. Endo N-hydroxy5-norbene-2,3-dicarboxylic acid imide was used as the internal standard. The conditions for ${ }^{31} \mathrm{P}$ NMR spectra were as follows: a $90^{\circ}$ pulse angle, $25 \mathrm{~s}$ pulse delay, and 256 transients at room temperature. 


\section{Adsorption of $\mathrm{CBH}$ onto lignin}

CBH (Cel7A; Megazyme E-CBH I), supplied at $10 \mathrm{mg}$ protein/ml, was from Trichoderma longibrachiatum. The binding of cellobiohydrolase I onto the lignin fractions was measured by the Langmuir isotherm protocol [43]. A range of concentrations of $\mathrm{CBH}$ were mixed with lignin samples $(2 \%, \mathrm{w} / \mathrm{v})$ and suspended in $\mathrm{pH} 4.8$ acetic acid-sodium acetate buffer. The mixture was kept at $50{ }^{\circ} \mathrm{C}$ until the adsorption was constant. The PierceTM bicinchoninic acid (BCA) protein assay from Thermo scientific was used for determination of protein concentration. Adsorption parameters such as the maximum adsorption capacity $\left(E_{\max }\right)$ and the equilibrium constant $\left(K_{\text {ads }}\right)$, were determined by linear regression of the adsorption data using the following equation.

$$
\left[E_{\mathrm{f}}\right] /\left[E_{\mathrm{ads}}\right]=1 /\left(K_{\mathrm{ads}}\left[E_{\mathrm{max}}\right]\right)+\left[E_{\mathrm{f}}\right] /\left[E_{\mathrm{max}}\right]
$$

where $\left[E_{\mathrm{f}}\right](\mathrm{mg} / \mathrm{ml})$ is the free protein concentration, $\left[E_{\text {ads }}\right](\mathrm{mg} / \mathrm{g})$ is the amount of protein adsorbed by the lignin, $K_{\text {ads }}$ is Langmuir adsorption constant, and [ $\left.E_{\max }\right]$ is the maximum amount of adsorbed protein.

\section{Additional file}

Additional file 1: Figure S1. 2D-HSQC spectra and the main structures of the isolated lignins: (A) $\beta$-aryl-ether units ( $\beta$-O-4); (B) phenylcoumarane; (C) resinols; (G) guaiacyl units; (S) syringyl units; (S') oxidized syringyl units bearing a carbonyl at $\mathrm{Ca}$; (PB) $\mathrm{p}$-Hydroxybenzoate units. Condensed lignin was assigned from Sun et al. [8].
Science \& Technology of Ministry of Education of China (No. KF-201409 and No. KF201611), key project of Hubei Provincial Department of Education (No. D20161402) and Foundation (No. 201611B01) of Hubei Provincial Key Laboratory of Green Materials for Light Industry. The research was conducted, in part, under BioEnergy Science Center (BESC) at Oak Ridge National Laboratory. BESC is a U.S. Department of Energy (DOE) Bioenergy Research Center supported by the Office of Biological and Environmental Research in the DOE Office of Science. Oak Ridge National Laboratory is managed by UT-Battelle, LLC, who authored the manuscript under Contract DE-AC05000R22725 with the U.S. Department of Energy. The publisher, by accepting the article for publication, acknowledges that the United States Government retains a nonexclusive, paid-up, irrevocable, worldwide license to publish or reproduce the published form of this manuscript, or allow others to do so, for United States Government purposes. The Department of Energy will provide public access to these results of federally sponsored research in accordance with the DOE Public Access Plan (http://energy.gov/downloads/doe-publi c-access-plan). The views and opinions of the authors expressed herein do not necessarily state or reflect those of the United States Government or any agency thereof. Neither the United States Government nor any agency thereof, nor any of their employees, makes any warranty, expressed or implied, or assumes any legal liability or responsibility for the accuracy, completeness, or usefulness of any information, apparatus, product, or process disclosed, or represents that its use would not infringe privately owned rights.

\section{Competing interests}

The authors declare that they have no competing interests.

\section{Ethics approval and consent to participate}

Not applicable.

\section{Publisher's Note}

Springer Nature remains neutral with regard to jurisdictional claims in published maps and institutional affiliations.

Received: 28 October 2017 Accepted: 11 January 2018

Published online: 04 April 2018

\begin{abstract}
Abbreviations
H: high recalcitrance poplar; L: low recalcitrance poplar; HSQC: heteronuclear single quantum coherence; $\mathrm{CBH}$ : cellobiohydrolase; FT-IR: Fourier transform infrared spectroscopy; S: syringyl; G: guaiacyl; GPC: gel permeation chromatography; $M_{n}$ : number average molecular weights; $M_{w}$ : weight average molecular weights; NMR: nuclear magnetic resonance; MWL: milled wood lignins; THF: tetrahydrofuran; HPLC: high performance liquid chromatography; DMSO- $d_{6}$ : deuterated dimethyl sulfoxide; TMDP: 2-chloro-4,4,5,5-tetramethyl-1,3,2-dioxaphospholane; PDI: polydispersity index.
\end{abstract}

\section{Authors' contributions}

LY and HTY performed the research, data analysis and drafted the manuscript. $C G Y, X M$ and $M L$ carried out the NMR experiments and revised the manuscript draft. YP and AJR analyzed the data and revised the manuscript. All authors read and approved the final manuscript.

\section{Author details}

${ }^{1}$ School of Pulp \& Paper Engineering, Hubei University of Technology, Wuhan 430068, China. ${ }^{2}$ Hubei Provincial Key Laboratory of Green Materials for Light Industry, Hubei University of Technology, Wuhan 430068, China. 3 Joint Institute for Biological Sciences, Biosciences Division, Oak Ridge National Laboratory, Oak Ridge, TN 37831, USA. ${ }^{4}$ Department of Chemical and Biomolecular Engineering, The University of Tennessee, Knoxville, TN 37996-2200, USA. ${ }^{5}$ Department of Forestry, Wildlife and Fisheries, Center for Renewable Carbon, Institute of Agriculture, The University of Tennessee, Knoxville, TN 37996-2200, USA.

\section{Acknowledgements}

The authors (i.e., L.Y., H.Y) are grateful for the support by National Natural Science Foundation of China (No. 31500496), China Scholarship Council (No. 2011842330 and No. 201508420257) and Key Laboratory of Pulp and Paper

\section{References}

1. Ragauskas AJ, Beckham GT, Biddy MJ, Chandra R, Chen F, Davis MF, Davison BH, Dixon RA, Gilna P, Keller M, Langan P, Naskar KA, Saddler JN, Tschaplinski TJ, Tuskan GA, Wyman CE. Lignin valorization: improving lignin processing in the biorefinery. Science. 2014;344:709-18.

2. Ralph J, Bunzel M, Marita JM, Hatfield RD, Lu F, Kim H, Schatz PF, Grabber $\mathrm{JH}$, Steinhart $\mathrm{H}$. Peroxidase-dependent cross-linking reactions of p-hydroxycinnamates in plant cell walls. Phytochem Rev. 2004;3:79-96.

3. Li X, Zheng Y. Lignin-enzyme interaction: mechanism, mitigation approach, modeling, and research prospects. Biotechnol Adv. 2017;35:466-89.

4. Radotic K, Micic M, Jeremic M. New insights into the structural organization of the plant polymer lignin. Ann N Y Acad Sci. 2005;1048:215-29.

5. Chernoglazov VM, Ermolova OV, Klyosov AA. Adsorption of high purity endo-1-4 glucanase from Trichoderma reesei on components of lignocellulosic materials: cellulose, lignin and xylan. Enzyme Microb Technol. 1988;10:503-7.

6. Sutcliffe R, Saddler JN. The role of lignin in the adsorption of cellulases during enzymatic treatment of lignocellulosic material. Biotechnol Bioeng Symp. 1986;17:749-62.

7. Saini JK, Patel AK, Adsul M, Singhania RR. Cellulase adsorption on lignin: a roadblock for economic hydrolysis of biomass. Renew Energy. 2016:98:29-42.

8. Sun S, Huang Y, Sun R, Tu M. Strong association of condensed phenolic moieties in isolated lignins with their inhibition of enzymatic hydrolysis. Green Chem. 2016;18:4276-86.

9. Pan X. Role of functional group in lignin inhibition of enzymatic hydrolysis of cellulose to glucose. J Biobased Mater Bioenergy. 2008;2:25-32.

10. Yu Z, Gwak K, Treasure T, Jameel H, Chang H, Park SK. Effect of lignin chemistry on the enzymatic hydrolysis of woody biomass. ChemSusChem. 2014;7:1942-50. 
11. Eriksson T, Börjesson J, Tjerneld F. Mechanism of surfactant effect in enzymatic hydrolysis of lignocellulose. Enzyme Microb Technol. 2002:31:353-64.

12. Nakagame S, Chandra RP, Kadla JF, Saddler JN. Enhancing the enzymatic hydrolysis of lignocellulosic biomass by increasing the carboxylic acid content of the associated lignin. Biotechnol Bioeng. 2011;108:538-48.

13. Qin C, Clarke K, Li K. Interactive forces between lignin and cellulase as determined by atomic force microscopy. Biotechnol Biofuels. 2014:7:65-74.

14. Berlin A, Balakshin M, Gilkes N, Kadla J, Maximenko V, Kubo S, Saddler J. Inhibition of cellulase, xylanase and beta-glucosidase activities by softwood lignin preparations. J Biotechnol. 2006;125:198-209.

15. Guo F, Shi W, Sun W, Li X, Wang F, Zhao J, Qu Y. Differences in the adsorption of enzymes onto lignins from diverse types of lignocellulosic biomass and the underlying mechanism. Biotechnol Biofuels. 2014;7:38-47.

16. Ko JK, Ximenes E, Kim Y, Ladisch MR. Adsorption of enzyme onto lignins of liquid hot water pretreated hardwoods. Biotechnol Bioeng. 2015;112:447-56

17. Tan L, Sun W, Li X, Zhao J, Qu Y, Choo YM, Loh SK. Bisulfite pretreatment changes the structure and properties of oil palm empty fruit bunch to improve enzymatic hydrolysis and bioethanol production. Biotechnol J. 2015;10:915-25.

18. Nonaka H, Kobayashi A, Funaoka M. Lignin isolated from steam-exploded eucalyptus wood chips by phase separation and its affinity to Trichoderma reesei cellulase. Bioresour Technol. 2013;140:431-4.

19. Nonaka H, Tanaka H, Funaoka M. Adsorption of Trichoderma reesei cellulase on softwood lignin-based lignophenol. J Jpn Inst Energy. 2011;90:977-81.

20. Palonen H, Tjerneld F, Zacchi G, Tenkanen M. Adsorption of Trichoderma reesei $\mathrm{CBH}$ I and $\mathrm{EG} I \mathrm{I}$ and their catalytic domains on steam pretreated softwood and isolated lignin. J Biotechnol. 2004;107:65-72.

21. Yoo C, Yang Y, Pu Y, Meng X, Muchero W, Yee KL, Thompson OA, Rodriguez M Jr, Bali G, Engle NL, Lindquist E, Singan V, Schmutz J, DiFazio SP, Tschaplinski TJ, Tuskan GA, Chen J, Davison B, Ragauskas AJ. Insights of biomass recalcitrance in Populus trichocarpa natural variants for biomass conversion. Green Chem. 2017;19:5467-78.

22. Yan S, LiT, Yao L. Mutational effects on the catalytic mechanism of cellobiohydrolase I from Trichoderma reesei. J Phys Chem B. 2011;115:4982-9.

23. Faix O. Classification of lignins from different botanical origins by FT-IR spectroscopy. Holzforschung. 1991:45:21-7.

24. Yang H, Xie Y, Zheng X, Pu Y, Huang F, Meng X, Wu W, Ragauskas A, Yao L. Comparative study of lignin characteristics from wheat straw obtained by soda-AQ and kraft pretreatment and effect on the following enzymatic hydrolysis process. Bioresour Technol. 2016;207:361-9.

25. Yuan T, He J, Xu F, Sun R. Fractionation and physico-chemical analysis of degraded lignins from the black liquor of Eucalyptus pellita KP-AQ pulping. Polym Degrad Stab. 2009;94:1142-50.

26. Samuel R, Pu Y, Raman B, Ragauskas AJ. Structural characterization and comparison of switchgrass ball-milled lignin before and after dilute acid pretreatment. Appl Biochem Biotechnol. 2010;162:62-74.

27. Cao S, Pu Y, Studer M, Wyman C, Ragauskas AJ. Chemical transformations of Populus trichocarpa during dilute acid pretreatment. RSC Adv. 2012:2:10925-36.
28. Pu Y, Cao S, Ragauskas AJ. Application of quantitative ${ }^{31}$ P NMR in biomass lignin and biofuel precursors characterization. Energy Environ Sci. 2011:4:3154-66.

29. Sadeghifar H, Wells T, Le RK, Sadeghifar F, Yuan JS, Ragauskas AJ. Fractionation of organosolv lignin using acetone: water and properties of the obtained fractions. ACS Sustain Chem Eng. 2017;5:580-7.

30. Cui C, Sun R, Argyropoulos DS. Fractional precipitation of softwood kraft lignin: isolation of narrow fractions common to a variety of lignins. ACS Sustain Chem Eng. 2014:2:959-68.

31. Li H, Pu Y, Kumar R, Ragauskas AJ, Wyman CE. Investigation of lignin deposition on cellulose during hydrothermal pretreatment, its effect on cellulose hydrolysis, and underlying mechanisms. Biotechnol Bioeng. 2014:3:485-92.

32. Wang $K$, Yang $H$, Yao X, Xu F, Sun R. Structural transformation of hemicelluloses and lignin from triploid poplar during acid-pretreatment based biorefinery process. Bioresour Technol. 2012;116:99-106.

33. Morreel K, Ralph J, Kim H, Lu F, Goeminne G, Ralph S, Messens E, Boerjan W. Profiling of oligolignols reveals monolignol coupling conditions in lignifying poplar xylem. Plant Physiol. 2004;136:3537-49.

34. Meng X, Pu Y, Yoo C, Li M, Bali G, Park D, Gjersing E, Davis F, Muchero W, Tuskan A, Tschaplinski J, Ragauskas J. An in-depth understanding of biomass recalcitrance using natural poplar variants as the feedstock. ChemSusChem. 2016;9:1-13.

35. Yang Q, Pan X. Correlation between lignin physicochemical properties and inhibition to enzymatic hydrolysis of cellulose. Biotechnol Bioeng. 2016;6:1213-24.

36. Mou H, Wu S. Comparison of hydrothermal, hydrotropic and organosolv pretreatment for improving the enzymatic digestibility of bamboo. Cellulose. 2017;24:85-94.

37. LiY, Qi B, Wan Y. Inhibitory effect of vanillin on cellulase activity in hydrolysis of cellulosic biomass. Bioresour Technol. 2014;167:324-30.

38. Nakagame S, Chandra P, Kadla F, Kadla F, Saddler N. The isolation, characterization and effect of lignin isolated from steam pretreated Douglas-fir on the enzymatic hydrolysis of cellulose. Bioresour Technol. 2011;102:4507-17.

39. Yao L, Yang H, Yoo C, Meng X, Li M, Pu Y, Ragauskas AJ, Sykes RW. Adsorption of cellobiohydrolases I onto lignin fractions from dilute acid pretreated Broussonetia papyrifera. Bioresour Technol. 2017;244:957-62.

40. Björkman A. Studies on finely divided wood. Part 1. Extraction of lignin with neutral solvent. Sven Papperstidn. 1956:59:477-85.

41. Kumar R, Hu F, Hubbell CA, Ragauskas AJ, Wyman CE. Comparison of laboratory delignification methods, their selectivity, and impacts on physiochemical characteristics of cellulosic biomass. Bioresour Technol. 2013;130:372-81.

42. Yoo C, Li M, Meng X, Pu Y, Ragauskas AJ. Effects of organosolv and ammonia pretreatments on lignin properties and its inhibition for enzymatic hydrolysis. Green Chem. 2017;19:2006-16.

43. Lu X, Zheng X, Li X, Zhao J. Adsorption and mechanism of cellulase enzymes onto lignin isolated from corn stover pretreated with liquid hot water. Biotechnol Biofuels. 2016;9:118-29.

Ready to submit your research? Choose BMC and benefit from

- fast, convenient online submission

- thorough peer review by experienced researchers in your field

- rapid publication on acceptance

- support for research data, including large and complex data types

- gold Open Access which fosters wider collaboration and increased citations

- maximum visibility for your research: over $100 \mathrm{M}$ website views per year

At BMC, research is always in progress.

Learn more biomedcentral.com/submissions 